Research letter

\title{
Comparison of zinc, copper, selenium, magnesium, aluminium and lead blood concentrations in end-stage renal disease patients and healthy volunteers in Ahvaz, southwest of Iran
}

\author{
Heshmatollah Shahbazian ${ }^{1}$, Abdorrahim Absalan ${ }^{2}$, Mohammad Taha Jalali ${ }^{1}$, Farideh Mastipour ${ }^{1}$, \\ Gholam Abbas Kaydani ${ }^{1}$, Zeinab Deris Zayeri ${ }^{1}$ \\ ${ }^{1}$ Ahvaz Jundishapur University of Medical Sciences, Ahvaz, Iran \\ ${ }^{2}$ Tarbiat Modares University, Tehran, Iran
}

Received 8 June 2017, Revised 12 October 2017, Accepted 16 November 2017

(C) 2017, Shahbazian H., Absalan A., Jalali M.T., Mastipour F., Kaydani G.A., Zayeri Z.D.

(C) 2017, Russian Open Medical Journal

\begin{abstract}
Introduction - Heavy metal storage and essential elements deficiency are two important issues in dialysis patients. Geographic region and dietary habits might affect essential trace elements concentration in body. Trace elements (TEs) status has not been studied previously in dialyzed patients in Ahvaz city. The aim of this study is to compare blood concentrations of six TEs between dialysis patients and normal group in Ahvaz, the center of Khuzestan province, in southwest of Iran.

Material and Methods - We studied 33 end-stage renal disease (ESRD) patients and 33 normal cases. TEs assayed in serum samples, except lead, which assessed in whole blood. We used atomic absorption spectroscopy in this pressure. We used ANOVA and Tukey-HSD statistical analysis as well as binary logistic regression for calculating Odds ratio.

Results - There was a significant difference between case and control groups for magnesium (Mg), aluminium (Al) and lead (Pb) $(\mathrm{P}<0.05)$, but there was not a significant difference for copper $(\mathrm{Cu})$ and selenium $(\mathrm{Se})(\mathrm{P}>0.05)$. Zinc $(\mathrm{Zn})$ level change was not significant. Al and $\mathrm{Pb}$ level increased after dialysis but Mg level decreased. All calculated Odds ratios were weak for all investigated trace elements. Different results published about TEs level in ESRD patients. Increase in TEs level in case group may be as a result of chronic poisoning through dialysis and after dialysis hemoconcentration, respectively. In order to understand the exact reason of this observation we need comprehensive and monitored studies. TEs disturbances in Ahvaz ESRD patients imply the importance of periodically studies.

Conclusion - The most important interpretations and suggestions of this study is that the TEs level is different among different population. Then, Iranian health-providers should consider to TEs assessment in both healthy and patient cases. Periodical measurement of TEs is essential for ESRD patients and it can be helpful in preventing TEs deleterious effects.
\end{abstract}

Keywords: end-stage renal disease, trace elements, poisoning, heavy metals, Khuzestan province

Cite as Shahbazian H, Absalan A, Jalali MT, Mastipour F, Kaydani GA, Zayeri ZD. Comparison of zinc, copper, selenium, magnesium, aluminium and lead blood concentrations in end-stage renal disease patients and healthy volunteers in Ahvaz, southwest of Iran. Russian Open Medical Journal 2018 ; 7: e0105.

Correspondence to Prof. Mohammad Taha Jalali. Tel.: 0613161159. E-mail: mohammadtahajalali@yahoo.com.

\section{Introduction}

Kidney has a critical role in balancing trace elements (TEs) concentration [1]. Kidney failure can cause health-threating problems and TEs disturbances [2-4]. Geographical region, dietary and nutritional habits are effective factors in TEs statue and lead it to be at tracer or toxic level $[5,6]$. The absence of data about each area soil content of minerals distribution or customary regimen in each country region is an important problem [6]. Obscures assessment of trace minerals turns to be essential in clinical decisions. recent studies suggest that long-term toxicity and cancer development, without any established effector-outcome correlation, seems to be as a result of toxic concentration of TES [5]. Meanwhile, there are strong evidence about the importance of geographical effect on TEs level and their impact on human health [1, 3-7]. TEs disturbance has been reported in end-stage renal disease (ESRD) patients [1-4, 8-12]. TEs level is populationdependent; it means that TEs level is various in patients and healthy cases and it may be different among different countries and cities. According to the Hosseinpanah and his cooperators report chronic kidney disease (CKD) prevalence is about $18.9 \%$ in Tehran the capital and the most crowded city of Iran [13]; Iran has 31 wide provinces and about 80 million population. Unfortunately, we have not comprehensive information about TEs status in other parts of Iran.

This study designed to evaluate trace or toxic element contents in healthy and ESRD patients in Khuzestan province, the southwest of Iran. Our information about body mineral contents would be helpful in prevention of ESRD. In this study we have determined two toxic elements aluminum (Al) and lead ( $\mathrm{Pb})$, and four essential mineral elements (zinc (Zn), selenium (Se), magnesium (Mg) and copper (Cu)) in ESRD patients and healthy individuals to compare TEs status. The aims of this study is gathering primary data about TEs status in ESRD patients and normal cases and assessing the importance of TEs measurement in ESRD patients. 
Table 1. Case and control categories data of trace elements, means with standard deviations, binary comparisons, calculated Odds ratio obtained from logistic regression and ANOVA results of three group variance analysis

\begin{tabular}{|c|c|c|c|c|c|c|}
\hline Elements & Categories & $N$ & $M \pm S D$ & Tukey HSD P-Value & OR $(95 \% \mathrm{Cl})$ & ANOVA P-Value \\
\hline \multirow[t]{3}{*}{$\mathrm{Zn}, \mathrm{mcg} / \mathrm{L}$} & Case (B.D) & 32 & $863.50 \pm 129.08$ & 0.263 & $1.00(0.99-1.00)$ & \\
\hline & Control & 33 & $808.00 \pm 117.66$ & $\uparrow \downarrow$ & $\uparrow \downarrow$ & $<0.001$ \\
\hline & Case (A.D) & 31 & $994.22 \pm 174.51$ & $<0.001$ & $0.99(0.98-1.00)$ & \\
\hline \multirow[t]{3}{*}{$\mathrm{Cu}, \mathrm{mcg} / \mathrm{L}$} & Case (B.D) & 32 & $750.38 \pm 164.70$ & 0.60 & $1.00(0.99-1.00)$ & \\
\hline & Control & 24 & $698.46 \pm 129.98$ & $\uparrow \downarrow$ & $\uparrow \downarrow$ & 0.617 \\
\hline & Case (A.D) & 31 & $736.63 \pm 262.68$ & 0.758 & $1.00(1.00-1.00)$ & \\
\hline \multirow[t]{3}{*}{$\mathrm{Se}, \mathrm{mcg} / \mathrm{L}$} & Case (B.D) & 31 & $107.15 \pm 14.97$ & 0.256 & $0.97(0.93-1.01)$ & \\
\hline & Control & 33 & $101.51 \pm 11.77$ & $\uparrow \downarrow$ & $\uparrow \downarrow$ & 0.229 \\
\hline & Case (A.D) & 32 & $106.35 \pm 15.65$ & 0.353 & $0.97(0.94-1.01)$ & \\
\hline \multirow[t]{3}{*}{$\mathrm{Mg}, \mathrm{mg} / \mathrm{dl}$} & Case (B.D) & 31 & $3.28 \pm 0.68$ & $<0.001$ & $0.00(0.00-0.05)$ & \\
\hline & Control & 33 & $2.07 \pm 0.30$ & $\uparrow \downarrow$ & $\uparrow \downarrow$ & $<0.001$ \\
\hline & Case (A.D) & 31 & $2.63 \pm 0.48$ & $<0.001$ & $0.00(0.00-0.06)$ & \\
\hline \multirow[t]{3}{*}{$\mathrm{Al}, \mathrm{mcg} / \mathrm{L}$} & Case (B.D) & 31 & $5.88 \pm 2.52$ & 0.003 & $0.64(0.49-0.84)$ & \\
\hline & Control & 33 & $3.43 \pm 2.44$ & $\uparrow \downarrow$ & $\uparrow \downarrow$ & $<0.001$ \\
\hline & Case (A.D) & 32. & $7.35 \pm 3.50$ & $<0.001$ & $0.50(0.36-0.71)$ & \\
\hline \multirow[t]{3}{*}{$\mathrm{Pb}, \mathrm{mcg} / \mathrm{L}$} & Case (B.D) & 33 & $27.13 \pm 6.46$ & $<0.001$ & $0.73(0.63-0.85)$ & \\
\hline & Control & 33 & $16.72 \pm 6.84$ & $\uparrow \downarrow$ & $\uparrow \downarrow$ & $<0.001$ \\
\hline & Case (A.D) & 32 & $28.35 \pm 3.89$ & 0.000 & $0.72(0.62-0.83)$ & \\
\hline
\end{tabular}

$\mathrm{M} \pm \mathrm{SD}$, means with standard deviations. Odds ratio is presented with its $95 \%$ confidence intervals $-\mathrm{OR}(95 \% \mathrm{Cl})$.

$\uparrow \downarrow$, in comparison with above or below row; B.D, before dialysis; A.D, after dialysis; mcg/L, micrograms per litter; mg/dl, milligrams per deciliters.

\section{Material and Methods}

In this study 33 ESRD patients and 33 healthy cases randomly selected from a university hospital of Ahvaz Jundishapur University of Medical Sciences (Ahvaz, Iran). Mean and standard deviation $(\mathrm{M} \pm \mathrm{SD})$ of patient and healthy group's age was $54.81 \pm 15.65$ for patient group and $50.09 \pm 9.7$ for healthy group respectively $(\mathrm{P}=0.154)$. In the patient group, there were $16(48.5 \%)$ males and 17 (51.5\%) females; in the healthy group, there were 19 (57.6\%) males and 14 (42.4\%) females.

Serum samples collected for $\mathrm{Zn}, \mathrm{Se}, \mathrm{Mg}, \mathrm{Cu}, \mathrm{Al}$ and whole blood samples in ethylenediamine tetraacetic acid (EDTA) containers collected for $\mathrm{Pb}$ measurements. Atomic absorption spectroscopy (Varian AA24o Atomic Absorption, USA) used to determination all of these elements. Determination of TEs was done on ESRD patient's samples before and after dialysis. Single determination of TEs was done on control group samples.

All elements wavelengths (W) determined by air-acetylene flame and $W$ of each element was $W_{\mathrm{Zn}}=213 \mathrm{~nm}, W_{\mathrm{Cu}}=324 \mathrm{~nm}$, $W_{S e}=196 \mathrm{~nm}, W_{M g}=279 \mathrm{~nm}, W_{\mathrm{Al}}=308 \mathrm{~nm}$, and $W_{\mathrm{Pb}}=217 \mathrm{~nm}$. An expert and specialized instrument operator did all measurements.

Statistical analysis was done by one-way analysis of variance (ANOVA) method and Tukey's honest significance test (Tukey-HSD) of Post-hoc multiple comparisons for separate comparison between two groups. In addition, Odds ratio values were calculated using binary logistic regression. The confidence interval (Cl) was considered in the range of $95 \%$ of normal distribution. SPSS ver.16 and Minitab ver.16 software were used for statistical analysis.

\section{Results}

Statistical analysis showed that there was a significant difference between all categories of subjects for serum $\mathrm{Zn}, \mathrm{Mg}, \mathrm{Al}$ and $\mathrm{Pb}(\mathrm{P}<0.001)$ but there was not a significant difference for $\mathrm{Cu}$ $(P=0.617)$ and $\mathrm{Se}(P=0.229)$ (Table 1$)$.

Post-Hoc multiple comparisons using Tukey-HSD analysis showed that there was a significant difference between healthy group and patient group after dialysis in concentrations of $\mathrm{Zn}$ $(P=0.000)$ but no significant difference with before dialysis $(P=0.263)$. For $\mathrm{Cu}$ serum levels there was not any meaningful difference between healthy group and before dialysis $(P=0.6)$ or after dialysis $(P=0.758)$. Same results were obtained for Se serum levels ( $P=0.256$ for before dialysis) and ( $P=0.353$ for after dialysis). However, there were significant differences between healthy group and patient group before and after dialysis for $\mathrm{Mg}$, Al and $\mathrm{Pb}$ $(P<0.05)$. Odds ratio for estimating the chances of undergoing kidney disease according to the TEs concentrations were highly weak and insignificant (Table 1).

\section{Discussion}

Assessment of TEs can not be a good criterion for predicting kidney problems, according to Odds ratios. Kamińska-Galwa and his cooperators showed that serum $\mathrm{Zn}, \mathrm{Cu}$ and Se levels of dialysis patients were lower than healthy cases they reported that concentrations of TEs decrease during hemodialysis [14]. This finding is in spite with our results for $\mathrm{Zn}$; Se and $\mathrm{Cu}$ serum concentrations; these TEs were higher, however not significant, in hemodialysis patients. This discrepancy can be as a result of the population's heterogenic nature or measurement technique sensitivity differences. Piechota and colleges have reported insignificant differences between ESRD patients and healthy group for $\mathrm{Zn}$ and $\mathrm{Cu}$ plasma levels but $\mathrm{Mg}$ level was higher in patients than control individuals [15]. Mansouri and his cooperators reported normal concentrations of $\mathrm{Zn}$ in uremic patients [16]. However Ellis reported low serum and plasma $\mathrm{Zn}$ but $\mathrm{Zn}$ urinary level showed increase status [17]. Gallery and coworkers have reported an acute $\mathrm{Zn}$ toxicity case who was on hemodialysis; their study implied the role of water resource that was used for hemodialysis. they suggested that a cumulative effect of dialysis for $\mathrm{Zn}$ caused poisoning [18]. Richard et al. have reported that serum $\mathrm{Zn}, \mathrm{Cu}$ and $\mathrm{Se}$ were decreased in dialyzed patients compared with normal controls [19]; such finding was in contrast to our results. According to the previous studies, $\mathrm{Cu}$ concentrations may be on the low or toxic levels in chronically 
dialyzed patients [20]. Various researchers reported different results for TEs. However, different dietary habits, geographical region of each area and the chance of exposure rate to each trace mineral may play a role in diversity of researcher's reports. Reports suggest that TEs evaluation is a neglected clinical assessment in Iran and only an expert clinician requests such test. Additionally severe TEs poisoning or deficiency may be diagnosed clinically by patient's history. Unfortunately most of clinical laboratories in Iran are not equipped with an atomic spectroscopic instrument to perform such tests. Nowadays, only chemical or biochemical colorimetric methods are used to measure some TEs such as $\mathrm{Mg}, \mathrm{Zn}$, Se and $\mathrm{Cu}$ however the accuracy of these assessments is under suspicious. Main issue about TEs in Iran is unfamiliarity of physicians and laboratory managers in Iran about the importance of TEs and their role in disease related conditions and disease development.

Lee et al. have reported low levels of plasma $\mathrm{Zn}$ in $78 \%$ of hemodialysis cases, high plasma $\mathrm{Al}$ in $31 \%$ but normal $\mathrm{Cu}$ and $\mathrm{Pb}$ in most cases. In their study, most healthy cases showed significantly lower level of $\mathrm{Al}$ and $\mathrm{Pb}$ in plasma in compare to patient group. Furthermore, $\mathrm{Cu}$ and $\mathrm{Zn}$ were higher in healthy group. These findings are in accordance with our results for $\mathrm{Al}$ and $\mathrm{Cu}$ in hemodialysis patients but not for $\mathrm{Zn}$. TEs level associate to various factors and imply the role of medications, environmental factors, diet and aging process [21]. Kazi et al. have shown that $\mathrm{Al}$ and $\mathrm{Pb}$ blood concentrations in chronic renal failure patients are significantly higher than healthy individuals; also dialysis reduce TEs concentration [22]. Jervis and coworkers showed that there is not any differences between Al contents of hair sample obtained from dialyzed patients and healthy groups [23]. As it is obvious, some studies confirm that $\mathrm{Al}$ and $\mathrm{Pb}$ may be overload in patients who are under dialysis; this finding was also obtained in our study.

In our study, obtained results showed that:

i) $\mathrm{Zn}$ serum level was higher than healthy group especially after dialysis; this finding suggest that $\mathrm{Zn}$ is added to the patient's blood stream during dialysis process or its concentrations raises due to the hemoconcentration phenomenon.

ii) $\mathrm{Cu}$ and Se serum levels were not changed significantly compared to normal group. Considering mentioned studies showed $\mathrm{Cu}$ and Se serum levels are expected to be lower than healthy group in our study, but our result was not so. It is suggested that there may be a balance between reception and delivery of these two elements during dialysis. However, it could not discussible prior to repetition and monitored assessments of TEs.

iii) Dialyzed patients have higher serum $\mathrm{Mg}$ levels even after dialysis; this may results to the chronic toxicity with Mg. Therefore, we suggest that $\mathrm{Mg}$ content assessment should be considered for chronically dialyzed patients.

iv) Serum $\mathrm{Al}$ and whole blood $\mathrm{Pb}$ levels increased after dialysis. Pre and post dialysis concentrations of $\mathrm{Al}$ and $\mathrm{Pb}$ were higher than healthy group.

\section{Conclusion}

This study implies the role of hemoconcentration phenomenon, which occurs after dialysis, or the addition of minerals to the blood flow during dialysis and via water resources used in dialysis process. Odds ratio analysis of current study showed that TEs level assessment is not associated with kidney disease. This may underestimate the importance of TEs ordering but we should not forget that TEs change is not the cause of kidney disease but it is a signature for kidney involvement, especially in the case of severe kidney diseases such as ESRD. Finally the most important interpretations and suggestions of the current study are these: the TEs variation is population dependent and TEs assessment should be considered by health-providers for Iranian's healthy and patient populations. Periodical measurement of TEs, both essential and toxic, for ESRD patients could be helpful for preventing deleterious effects. Iranian's clinicians should be familiar with the importance of trace minerals measurements and order TEs measurement by gold standard methods such as atomic absorption. Clinical laboratories should be equipped with the instruments assessing TEs, especially hospitals that admit ESRD or dialysis patients. Healthy populations also should be assessed for TEs because there isn't any data, such as Khuzestan province.

\section{Acknowledgments}

Ahvaz Jundishapur University of Medical Sciences grants this work. Then, authors make special thanks to their coworkers and patients who made kindly sharing for performing this study. Further, we thanks gratefully from Mr.Mohsen Ghasemi for his technical support about trace element measurement.

\section{Conflicts of interest}

The authors declare no conflict of interest.

\section{Ethical approval}

All procedures performed in studies involving human participants were in accordance with the ethical standards of the institutional and national research committee and with the 1964 Helsinki declaration and its later amendments or comparable ethical standards.

\section{References}

1. Kasama RK. Trace minerals in patients with end-stage renal disease. Semin Dial 2010; 23(6): 561-570. https://dx.doi.org/10.11613/BM.2015.021.

2. Locatelli F, Andrulli S, Pecchini F, Pedrini L, Agliata S, Lucchi L, et al. Effect of high-flux dialysis on the anaemia of haemodialysis patients. Nephrol Dial Transplant 2000; 15(9): 1399-1409. https://dx.doi.org/10.1093/ndt/15.9.1399.

3. Tonelli M, Wiebe N, Hemmelgarn B, Klarenbach S, Field C, Manns B, et al. Trace elements in hemodialysis patients: a systematic review and meta-analysis. $\quad B M C \quad$ Medicine 2009; 7(1): 25. https://dx.doi.org/10.1186/1741-7015-7-25.

4. Vanholder R, Cornelis R, Dhondt A, Lameire N. The role of trace elements in uraemic toxicity. Nephrol Dial Transplant 2002; 17(suppl 2): 2-8. https://dx.doi.org/10.1093/ndt/17.suppl 2.2.

5. Silvera SAN, Rohan TE. Trace elements and cancer risk: a review of the epidemiologic evidence. Cancer Causes Control 2007; 18(1): 7-27. https://dx.doi.org/10.1007/s10552-006-0057-z.

6. Gupta AP, Gupta S. Elemental profiling: its role and regulations. In: Atomic Absorption Spectroscopy. M.A. Farrukh, ed. InTech, 2012: 3760

7. Flaten TP. Geographical associations between aluminium in drinking water and death rates with dementia (including Alzheimer's disease), Parkinson's disease and amyotrophic lateral sclerosis in Norway. Environ Geochem Health 1990; 12(1): 152-167. https://dx.doi.org/10.1007/bf01734064. 
8. Jarup L, Akesson A. Current status of cadmium as an environmental health problem. Toxicol Appl Pharmacol 2009; 238(3): 201-208. https://dx.doi.org/10.1016/i.taap.2009.04.020.

9. Vanholder R, Van Loo A, Dhondt A, De Smet R, Ringoir S. Influence of uraemia and haemodialysis on host defence and infection. Nephrol Dial Transplant 1996; 11(4): 5938. https://dx.doi.org/10.1093/ndt/11.4.593.

10. Malluche $\mathrm{HH}$. Aluminium and bone disease in chronic renal failure. Nephrol Dial Transplant 2002; 17 (Suppl 2): 21-24. https://dx.doi.org/10.1093/ndt/17.suppl 2.21.

11. Cannata-Andia JB, Fernandez-Martin JL. The clinical impact of aluminium overload in renal failure. Nephrol Dial Transplant 2002; 17 (Suppl 2): 9-12. https://dx.doi.org/10.1093/ndt/17.suppl 2.9.

12. Minoia C, Sabbioni E, Apostoli P, Pietra R, Pozzoli L, Gallorini M, et al. Trace element reference values in tissues from inhabitants of the European community. I. A study of 46 elements in urine, blood and serum of Italian subjects. Sci Total Environ 1990; 95: 89-105. https://dx.doi.org/10.1016/0048-9697(90)90055-Y.

13. Hosseinpanah F, Kasraei F, Nassiri AA, Azizi F. High prevalence of chronic kidney disease in Iran: a large population-based study. BMC Public Health 2009; 9: 44. https://dx.doi.org/10.1186/1471-2458-9-44.

14. Kamińska-Galwa B, Grzeszczak W, Jedryczko A, Pachelski J. Influence of long-term hemodialysis on serum trace elements concentration in patients with chronic renal failure. Przeg/ Lek 1994; 51(1): 9-14. Polish. https://www.ncbi.nlm.nih.gov/pubmed/8209000.

15. Piechota W, Dobrucki T, Symonowicz N, Wadowska E, Murkowska E. Zinc in patients with chronic renal failure. Int Urol Nephrol 1983; 15(4): 377-382. https://www.ncbi.nlm.nih.gov/pubmed/6662654.

16. Mansouri K, Halsted JA, Gombos EA. Zinc, copper, magnesium and calcium in dialyzed and nondialyzed uremic patients. Arch Intern Med 1970; 125(1): 88-93. https://dx.doi.org/10.1001/archinte.1970.00310010090007.

17. Ellis L. Serum zinc levels and urinary zinc excretion in patients with renal transplants. Clinica Chimica Acta 1978; 82(1-2): 105-111. https://dx.doi.org/10.1016/0009-8981(78)90032-3.

18. Gallery ED, Blomfield J, Dixon SR. Acute zinc toxicity in haemodialysis. $\mathrm{Br}$ Med J 1972; 4(5836): 331-333. https://dx.doi.org/10.1136/bmj.4.5836.331.

19. Richard MJ, Arnaud J, Jurkovitz C, Hachache T, Meftahi H, Laporte F, et al. Trace elements and lipid peroxidation abnormalities in patients with chronic renal failure. Nephron 1991; 57(1): 10-15. https://dx.doi.org/10.1159/000186208.

20. Emenaker NJ, DiSilvestro RA, Nahman Jr NS, Percival S. Copper-related blood indexes in kidney dialysis patients. Am J Clin Nutr 1996; 64(5): 757-760. https://www.ncbi.nlm.nih.gov/pubmed/8901797.

21. Lee SH, Huang JW, Hung KY, Leu LJ, Kan YT, Yang CS, et al. Trace Metals' abnormalities in hemodialysis patients: relationship with medications. Artificial Organs 2000; 24(11): 841-844. https://dx.doi.org/10.1046/j.1525-1594.2000.06352.x.

22. Kazi TG, Jalbani N, Kazi N, Jamali MK, Arain MB, Afridi $\mathrm{HI}$, et al. Evaluation of toxic metals in blood and urine samples of chronic renal failure patients, before and after dialysis. Renal Failure 2008; 30(7): 737-745. https://dx.doi.org/10.1080/08860220802212999.

23. Jervis RE, Kua BT, Hercz G. Hair trace elements in kidney dialysis patients by INAA. Biol Trace Elem Res 1994; 43-45: 335-342. https://dx.doi.org/10.1007/BF02917333.

Authors:

Heshmatollah Shahbazian - Nephrology Specialist, Professor, Chronic Kidney Disease Research Center, Ahvaz Jundishapur University of Medical Sciences, Ahvaz, Iran. http://orcid.org/0000-0002-1463-5790.

Abdorrahim Absalan - PhD, Professor, Department of Clinical Biochemistry, Faculty of Medical Sciences, Tarbiat Modares University, Tehran, Iran. http://orcid.org/0000-0001-9661-3511.

Mohammad Taha Jalali - Professor, Department of Laboratory Medicine, Faculty of Paramedical Sciences, Ahvaz Jundishapur University of Medical Sciences, Ahvaz, Iran. http://orcid.org/0000-0002-5094-8049.
Farideh Mastipour - BSc of Nursing, Nurse, Golestan Hospital, Ahvaz Jundishapur University of Medical Sciences, Ahvaz, Iran.

Gholam Abbas Kaydani - PhD, Assistant Professor, Department of Laboratory Medicine, Faculty of Paramedical Sciences, Ahvaz Jundishapur University of Medical Sciences, Ahvaz, Iran. http://orcid.org/0000-00030324-3238.

Zeinab Deris Zayeri - MSc (Human Genetic), Clinical laboratorian, Golestan Hospital Clinical Research Development Unit, Ahvaz Jundishapur University of Medical Sciences, Ahvaz, Iran. http://orcid.org/0000-0002-8621-5904. 